\title{
A Year Retrospective Study on the Morbidity and Mortality Pattern of Covid-19 Patients in an Isolation Facility in Benin City, Nigeria
}

\section{Endurance 0. Evbayekha MD1, Ovie Okorare MD², Okelue E. Okobi MD ${ }^{3 *}$, M.Sc, Gabriel Alugba MD², Nnenna A. Ukoha MD", Rachael Agbator MD5, Henry Elukeme MD', Evidence E. Ohikhuai Pharm. ${ }^{7}$}

\author{
${ }^{1}$ Stella Obasanjo Isolation Center, Benin City, Nigeria \\ ${ }^{2}$ Delta State University, Abraka, Nigeria \\ ${ }^{3}$ Lakeside Medical Center, Belle Glade, Florida, USA \\ ${ }^{4}$ Royal Cross Methodist Hospital, Abia, Nigeria \\ ${ }^{5}$ Baptist Health University of Arkansas Medical Science, North Little Rock, USA \\ 6Floyd Medical Center, Rome, USA \\ ${ }^{7}$ Federal Neuro Psychiatric Hospital, Benin City, Nigeria \\ *Corresponding author details: Okelue E. Okobi MD; Drokelue.e.okobi@gmail.com
}

\begin{abstract}
A year after detecting the first COVID-19 case in Nigeria, data on the trend and pattern of morbidity and mortality are still emerging. Therefore, this study identifies the outcome of patients with COVID-19 in an isolation and treatment facility in Nigeria. This was a retrospective analysis of medical records for 327 laboratory-confirmed cases of COVID-19 patients in Stella Obasanjo Hospital, Benin, Edo state, South-South Nigeria. Extracted data included age, sex, comorbidities, the severity of illness, duration of hospitalization. Data was analyzed using the IBM SPSS version 22 software. Values $<0.05$ were regarded as significant. The majority of the study population were males (63.2\%), and the mean age was 44.5 years. 146 participants had at least one comorbidity, with hypertension $(61.5 \%)$ and diabetes $(17.1 \%)$ being the most common. The mortality rate was (12.5\%), and a higher proportion of patients with comorbidities died compared to those with no comorbidity. The trend of the morbidity and mortality pattern of patients with COVID-19 within the isolation and treatment facility showed higher adverse outcomes among those who presented with comorbid illnesses. Therefore, public enlightenment, vaccination, early detection, and targeted care for COVID-19 cases, especially those with comorbidities, are recommended.
\end{abstract}

Keywords: morbidity; mortality; COVID-19; retrospective study; isolation facility; Nigeria

\section{INTRODUCTION}

SARS-CoV-2, the novel virus causing Coronavirus disease 2019 (COVID-19), is the 7th of the coronavirus family reported to cause varying severity of respiratory tract infections in humans. It was first isolated and reported in Hubei province, China, in December 2019 [1]. The highly contagious SARS-CoV-2 rapidly spread across the globe and was declared a public health emergency of international concern by the World Health Organization (WHO) on January 30, 2020, and in less than two months (March 11, 2020), declared a Pandemic [2]. Globally, as of April 2, 2021, Covid-19 has led to significantly high morbidity and mortality of about 130.24 million confirmed cases and 2.84million deaths, respectively [3].

Africa is the last continent to be affected by the pandemic, reporting its first Case on February 14, 2020, in Egypt [1].
Current statistics (April 2, 2021) showed that African countries accounted for about $3.3 \%$ and $4 \%$ of the 130.24 million cases and 2.84million deaths reported globally [3]. In sub-Saharan Africa, Nigeria ranks among the top 5 countries with the highest number of confirmed COVID-19 cases [4]. Reports on April 2, 2021, showed 163,063 confirmed cases and an estimated 2058 deaths. This puts its current Case Fatality Ratio (CFR) at 1.26\%, a significant decline from $2.5 \%$ on March 14, 2020 [3]. Several measures to reduce the burden of morbidity and mortality on the health care system and economy at large included the creation of Isolation centers, intensified surveillance, contact tracing, increased testing capacity, social distancing amongst others [5]. In response to the outbreak, different states of the federation in collaboration with the private sector in the various states established various testing centers, dedicated isolation, and treatment centers for COVID-19 patients [6]. 
Edo state, which is in the South-South region of Nigeria, has five isolation and treatment centers located at strategic positions within its three senatorial districts [7]. Initially, all confirmed cases were admitted into the isolation and treatment centers, with most cases being mild to moderate during the early stages of the outbreak [8]. However, there has been a policy shift to home-based care by some states for mild cases. This has been properly coordinated in order to accurately identify groups at risk so as to inform risk communication to communities and early management of COVID-19 [4].

The severity and progression of the COVID-19 have been associated with pre-existing comorbidities such as hypertension, diabetes, obesity, chronic obstructive pulmonary disease, and cerebrovascular disease as seen from studies in the US and China [9]. Covid-19 disease morbidity and mortality patterns in patients varied significantly among countries owing to differences in health care systems, prevalence and availability of diagnostic testing, and patient characteristics - such as being elderly and or the presence of various comorbidities [10]. An estimated 5 percent of people have been posited by the WHO to need intensive care treatment, which can include being sedated and put on a ventilator [11].

This study aims to identify the morbidity and mortality pattern of COVID-19 patients in an isolation facility in the South-South region of Nigeria.

\section{MATERIALS \& METHODS}

This study is a retrospective, observational, descriptive design. It was carried out at the Stella Obasanjo Specialist Hospital Benin City, Edo State, Nigeria, a designated isolation facility for managing Covid-19 patients. Records of Covid-19 patients were retrieved from case notes of patients admitted between March 2020 and April 2020. Information retrieved include age, sex, comorbidity, duration of hospital stays and outcome. Severity criteria was as follows; Mild disease in asymptomatic patients with SOa2 more than 95 and respiratory rate less than 20 breaths per minute, moderate disease in patients with symptoms $\mathrm{SaO} 2$ more than 90 and respiratory rate between 20 to 30 breaths per minute, severe disease in patients with symptoms with $\mathrm{SaO} 2$ less than 90 needing oxygen therapy. Covid-19 was confirmed in patients with a positive polymerase chain reaction test. Data was analyzed using the IBM SPSS version 22 software. Values $<0.05$ were regarded as significant.

All PCR positive confirmed COVID-19 patients admitted between March 2020 and and April 2021

We excluded patients with incomplete or inaccessible medical records. We excluded patients with a positive COVID test but were asymptomatic and managed in their homes. Patients with COVID-like symptoms but with negative COVID-19 PCR results were also excluded.

Data was extracted from medical records.

RESULTS

TABLE 1: AGE AND GENDER PATTERN OF ADMITTED PATIENTS

\begin{tabular}{|l|c|c|}
\hline \multicolumn{1}{|c|}{ Age(years) } & Frequency(n) & Percent (\%) \\
\hline$<19$ & 12 & 3.7 \\
\hline $20-39$ & 145 & 44.3 \\
\hline $40-59$ & 110 & 33.6 \\
\hline $60-79$ & 59 & 18.0 \\
\hline $80-99$ & 7 & 2.1 \\
\hline Mean \pm SD $\quad 44.5 \pm 34.5$ & \\
\hline \multicolumn{1}{|c|}{ Gender } & Frequency(n) & Percent (\%) \\
\hline Male & 215 & 63.2 \\
\hline Female & 112 & 36.8 \\
\hline Total & 327 & 100.0 \\
\hline Severity pattern of cases & Frequency(n) & Percent (\%) \\
\hline Mild & 173 & 53.0 \\
\hline Moderate & 99 & 30.2 \\
\hline Severe & 55 & 16.8 \\
\hline
\end{tabular}

TABLE 2: CLINICAL CHARACTERISTICS OF PATIENTS

\begin{tabular}{|l|c|c|}
\hline \multicolumn{1}{|c|}{ Comorbidity pattern } & Frequency (n) & Percent (\%) \\
\hline Hypertension & 209 & 61.5 \\
\hline Diabetes & 58 & 17.1 \\
\hline Obesity & 53 & 15.6 \\
\hline Asthma & 5 & 1.5 \\
\hline Peptic Ulcer & 37 & 10.9 \\
\hline Cerebrovascular Disease & 5 & 1.5 \\
\hline Renal Impairment & 48 & 14.1 \\
\hline psychosis & 7 & 2.1 \\
\hline
\end{tabular}




\begin{tabular}{|l|c|c|}
\hline NUMBER OF COMORBIDITIES & Frequency (n) & Percent (\%) \\
\hline 0 & 179 & 52.6 \\
\hline 1 & 83 & 24.4 \\
\hline 2 & 60 & 17.6 \\
\hline $3 \quad \begin{array}{c}\text { Respiratory rate at presentation } \\
\text { (breaths per minute) }\end{array}$ & Frequency (n) & Percent (\%) \\
\hline$<20 \quad 198$ & 60.6 \\
\hline $20-30 \quad$ Symptoms at Presentation & Frequency (n) & 29.4 \\
\hline$>30 \quad 154$ & Percent (\%) \\
\hline & 135 & 45.3 \\
\hline Fever & 52 & 39.7 \\
\hline Cough & 101 & 15.3 \\
\hline Rhinitis & & 29.7 \\
\hline Breathlessness & 33 & 10.1 \\
\hline
\end{tabular}

TABLE 3: MORBIDITY AND MORTALITY PATTERN OF ADMITTED PATIENTS

\begin{tabular}{|c|c|c|c|}
\hline AGE GROUP & DISCHARGED n (\%) & DIED n (\%) & p Value \\
\hline$<19$ & $12(4.2)$ & $0(0)$ & 0.0002 \\
\hline $20-39$ & $143(49.8)$ & $2(4.9)$ & $<0.0001$ \\
\hline $40-59$ & $102(35.8)$ & $8(19.5)$ & 0.0004 \\
\hline $60-79$ & $29(10.2)$ & $24(58.8)$ & 0.1477 \\
\hline $80-99$ & $0(0.0)$ & $7(17.7)$ & $<0.0001$ \\
\hline SEX & DISCHARGED n (\%) & DIED n (\%) & p Value \\
\hline MALE & $187(65.3)$ & $28(65.9)$ & $<0.0001$ \\
\hline FEMALE & $99(34.6)$ & $13(34.1)$ & $<0.0001$ \\
\hline NUMBER OF COMORBIDITIES & DISCHARGED n (\%) & DIED n (\%) & p Value \\
\hline 0 & $177(61.8)$ & $2(4.9)$ & $<0.0001$ \\
\hline 1 & $65(22.8)$ & $18(43.9)$ & $<0.0001$ \\
\hline 2 & $40(14.0)$ & $20(44.8)$ & $<0.0001$ \\
\hline 3 & $2(0.7)$ & $1(2.4)$ & 0.2932 \\
\hline SEVERITY & DISCHARGED n (\%) & DIED n (\%) & p Value \\
\hline MILD & $169(58.9)$ & $2(4.9)$ & $<0.0001$ \\
\hline MODERATE & $97(34.0)$ & $2(4.9)$ & $<0.0001$ \\
\hline SEVERE & $18(6.3)$ & $37(90.2)$ & $<0.0001$ \\
\hline
\end{tabular}

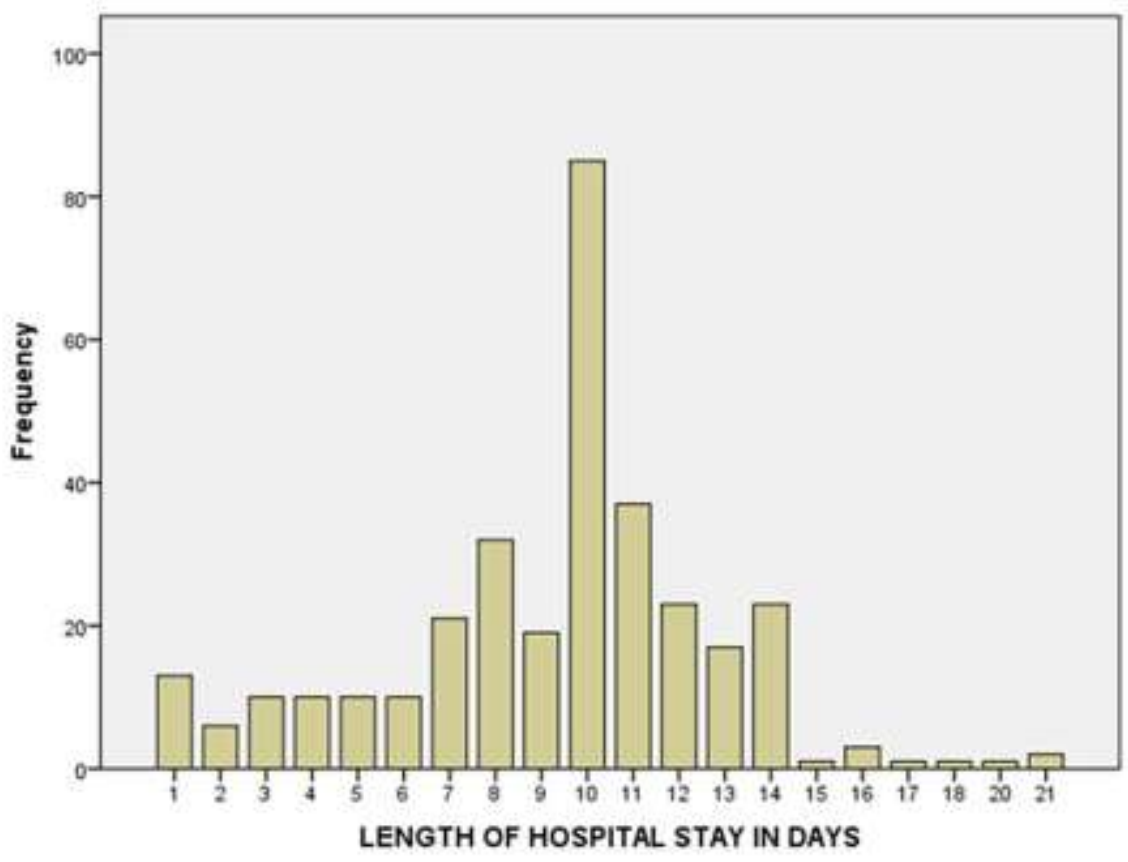

FIGURE 1: BAR CHART SHOWING THE AVERAGE LENGTH OF HOSPITAL ADMISSION (DAYS) 


\section{DISCUSSION}

Research on the disease characteristics of covid-19 infection in the Nigerian population is limited. Examining the disease pattern, morbidity, and mortality of this novel virus is important to study trends and as a prognostic tool for the teeming population of Africa's most populous nation.

In this study, we classified the disease into mild, moderate and severe based on the Nigerian national guideline of COVID 19 severity classification.

This study comprised 327 admitted patients in an isolation center in South-South Nigeria, 215 (63.2\%) were males and 112 were females (36.8\%). Similar studies in SouthWestern Nigeria showed $74.7 \%$ male preponderance [12] and $65.8 \%$ male [4]. Global data indicated a higher covid19 case fatality rate among men than women [13]. Factors implicated for this disparity include a higher expression of Angiotensin-Converting Enzyme-2, higher levels of alcohol consumption and smoking in the males. Immunological differences between the sexes driven by sex hormone and the $\mathrm{X}$ chromosome and the more responsible attitude of the female towards the pandemic [14]. More middle-aged persons were affected by covid-19 with a Mean age (SD) of $44.5 \pm 34.5$. This is in line with similar articles from Nigeria, with a mean age of 46.16 and a median age of 43 years (IQR: 33-55) [4].

The highest proportion of cases admitted (44\%) were between ages 20-39 years. However, in the analysis from a Nigerian national surveillance dataset, the highest proportion of COVID-19 cases and deaths were recorded in persons aged $31-40$ years (25.5\%) [15]. This age group may be most affected because they are more "economically active," hence more prone to exposure to the covid-19 infection.

Hypertension was the most predominant comorbidity amongst the study population which is similar to cases in developed nations like the US and China. This is probably as a result of the transition of lifestyle in the sub-Saharan region to that of the western countries, which has brought about an upsurge of non-communicable diseases with coexisting longstanding burden of infectious diseases.

Statistics about the prevalence of hypertension, diabetes in Nigeria is on the rise as it is $28.9 \%$ and $5.77 \%$ [16] respectively, with chronic kidney disease about $11.4 \%$ using the CKD-EPI equation. Due to lack of awareness, poor health seeking behavior, fear, misconceptions, reliance on unorthodox treatment, there is a large pool of undiagnosed cases within the population. It is known that some of these comorbidities tend to coexist in patients most commonly hypertension and diabetes, and our findings showed that having multiple comorbidities increases the risk of death from COVID-19. In a similar study, patients with two or more comorbidities were about four times more likely to die than those with one comorbidity [4].

Unlike other studies in developed countries [12], COPD and HIV were not seen in patients in this study, this is possibly due to the largely undiagnosed cases of COPD in Africa, however HIV is predominant in sub-Saharan Africa where risk factors are majorly dependent on lifestyle behaviors and vertical transmission, while that of COPD such as tobacco smoking, biomass smoke exposure, pulmonary tuberculosis are vastly prominent in Nigeria.

We encountered a higher mortality rate of $12.5 \%$ compared to another study from Lagos, South western Nigeria [12], which had a mortality of $2.6 \%$ and another
$3.3 \%$ [4]. This is possibly because our cohort was made up of mostly moderately to severely ill patients as more mildly ill patients were managed at home and excluded from this study. Home based care of mildly symptomatic COVID-19 was instituted by the NCDC in accordance with the WHO guidelines, this was as a result of sharp and steady rise of cases within the population and the increasing burden it placed on the health care system, the measures included the assessment and feasibility of care provision in a residential setting by an assigned health care worker, education on hygiene and infection prevention and control (IPC) measures for suspected COVID-19 cases and family members [17].

It was observed from the study that male patients were twice as likely to die from COVID-19 than female patients and the risk of death was higher among patients that were 60 years and older. This pattern is similar to global trends [18]. Suggested reasons for the higher morbidity and mortality of male patients include behavioral, social and biological differences that favor females [18].

Additional findings in our study showed that a high percentage (over $80 \%$ ) of patients were hospitalized for about 10-11 days, this corresponds to a study carried out in southwestern Nigeria, where the median hospital stay was 12 days (IQR: 9-13.5). The length of time taken to conduct the laboratory test and get two negative results lengthened the hospital stay in our study, this is also similar to another study conducted in southwestern Nigeria [8]. The burden on the limited medical resources by the increasing hospital stay, especially as more admissions were warranted during the pandemic was also considered.

Our work goes on to confirm existing trends from the few covid-19 related work from Nigeria.

\section{CONCLUSIONS}

This study described the outcome of COVID-19 cases within an isolation and treatment facility in the SouthSouth region of Nigeria, showing an increasing trend in mortality of patients with comorbidities compared to those with none. Interventions like public enlightenment, vaccination adoption, early detection and targeted care for COVID-19 cases especially those with comorbidities are recommended, in addition to other public health measures.

The robust NCDC guidelines placed emphasis on capacity building in order to prevent, detect and adequately respond to COVID-19 cases, reducing community transmission and providing support to health care facilities to expectedly identify, diagnose potential cases and manage confirmed cases. This stems from Nigeria's experience with fatal epidemic outbreaks such as Ebola Virus Disease, Lassa fever, which led to the development of strategies to combat future infectious epidemics including the establishment of various infectious disease centers, quarantine and isolation centers.

\section{Ethics Statement and Conflict of Interest Disclosures}

\section{Statements of ethical approval for studies involving human subjects and/or animals:}

- This study was approved by the Edo State Hospital Management Board Ethical committee and a waiver of Consent was obtained for this case series as this retrospective observational study poses minimal risk of harm to the subjects. We confirm that the study was conducted in accordance with Helsinki Declaration as revised in 2013 


\section{Human subjects:}

Consent was obtained or waived by all participants in this study. Hospital Management Board Ethics Committee Edo State Benin City Nigeria issued approval Not Applicable. Consent was obtained or waived by all participants in this study. Hospital Management Board Ethics Committee Edo State Benin City Nigeria issued approval Not Applicable. Our Ref: EC/QDI/01/04/20 Dear Principal Investigator: Telephone: HOSPITALS MANAGEMENT BOARD EDO STATE OF NIGERIA P.M.B. 1009 STELLA OBASANJO HOSPITAL BENIN. 04/01/2020

Animal subjects: All authors have confirmed that this study did not involve animal subjects or tissue.

Conflicts of interest: In compliance with the ICMJE uniform disclosure form, all authors declare the following: The Authors do not have no conflict of interest to declare.

Payment/services info: All authors have declared that no financial support was received from any organization for the submitted work.

Financial relationships: All authors have declared that they have no financial relationships at present or within the previous three years with any organizations that might have an interest in the submitted work.

Other relationships: All authors have declared that there are no other relationships or activities that could appear to have influenced the submitted work.

\section{REFERENCES}

[1] Shabir A. Lone, Aijaz Ahmad: COVID-19 pandemic - an African perspective. Taylor \& Francis.

[2] M. Kariuki Njenga, Jeanette Dawa, Mark Nanyingi, et al.: Why is there low morbidity and mortality of COVID-19 in Africa? PubMed Central.

[3] Nabamallika Dehingia, Anita Raj.: Sex Differences in COVID-19 Case Fatality: do we Know Enough?

[4] Akin Osibogun, Mobolanle Balogun, Akin Abayomi, et al.: Outcomes of COVID-19 patients with comorbidities in Southwest Nigeria. PLOS.

[5] John E. Hagan, Bright O. Ahinkorah, Abdul-Aziz Seidu, et al.: Africa's COVID-19 situation in focus and recent happenings: A mini review. Frontiers.

[6] Ramin Hosseinzadeh, Mohammad A. Sheikh, Beig Goharrizi, et al.: 15:2019.

[7] Usman A. Bello. (2020, April 6: 19. https://allafrica.com/stories/202004060065.html.
[8] Abimbola Bowale, Akin Abayomi, Jide Idris, et al.: Clinical presentation, case management and outcomes for the first. 32:19.

[9] Wei-Jie Guan, Wen-Hua Liang, Yi Zhao, et al.: Comorbidity and its impact on 1590 patients with COVID-19 in China: A nationwide analysis. PubMed. $10.1183 / 13993003.00547-2020$

[10] N. David Yanez, Noel S. Weiss, Jacques-André Romand, et al.: COVID-19 mortality risk for older men and women. BMC Public Health. https://bmcpublichealth.biomedcentral.com/articles/ 10.1186/s12889-020-09826-8.

[11] Gallagher, J.: Coronavirus: How Long Does it Take to Recover? BBC News.

[12] Ngozi M Otuonye., Testimony J. Olumade, Mercy M. Ojetunde, et al.: Clinical and demographic characteristics of COVID-19 patients in Lagos, Nigeria: A descriptive study. PubMed Central. https://www.ncbi.nlm.nih.gov/pmc/articles/PMC77 $59120 /$.

[13] Nabamallika Dehingiaa, Anita Raja. (2021, January 9: Sex differences in COVID-19 case fatality: Do we know enough? PubMed Central.

[14] George M. Bwire. (2020, June 4: Coronavirus: Why men are more vulnerable to COVID-19 than women? PubMed Central.

[15] K. O. Elimian, C. L. Ochu, E. Ilori, et al.: Descriptive epidemiology of coronavirus disease 2019 in Nigeria, 27 February-6 June. 2020.

https://www.ncbi.nlm.nih.gov/pmc/articles/PMC75 06173/.

[16] Andrew E. Uloko, Esther N. Ofoegbu, Sunday Chinenye, et al.: Profile of nigerians with diabetes mellitus - Diabcare Nigeria study group (2008): Results of a multicenter study - PubMed. PubMed. Indian J Endocrinol Metab. (ed): Indian J Endocrinol Metab. , 2012.10.4103/2230-8210.98011

[17] Olayinka S. Ilesanmi1, Aanuoluwapo A. Afolabi. (2020, December 8: A scope review on home-based care practices for COVID- 19: What Nigeria can learn from other countries. Ibom Medical Journal - open access peer reviewed triannual biomedical journal.

[18] Garima Sharma, Annabelle S. Volgman, Erin D. Michos. (2020, May 4: Sex differences in mortality from COVID-19 pandemic: Are men vulnerable and women protected? PubMed Central. 